\title{
A New Intronic Mutation in the DPM1 Gene Is Associated With a Milder Form of CDG Ie in Two French Siblings
}

\author{
JULIA DANCOURT, SANDRINE VUILLAUMIER-BARROT, HELENE OGIER DE BAULNY, IGNACIO SFAELLO, \\ ANNE BARNIER, CHRISTIANNE LE BIZEC, THIERRY DUPRE, GENEVIEVE DURAND, NATHALIE SETA, \\ AND STUART E.H. MOORE
}

\begin{abstract}
INSERM U 504 [J.D., T.D., S.E.H.M.], Villejuif 94807, France; Neurologie et maladies métaboliques [H.O.B., I.S.], Hôpital Robert Debré, Paris 75019, France; Biochimie A [S.V.-B., A.B., C.B., T.D., G.D., N.S.], Hôpital Xavier Bichat, Paris 75018, France
\end{abstract}

\begin{abstract}
Congenital disorders of glycosylation (CDG) type I (CDG I) are rare autosomal recessive diseases caused by deficiencies in the assembly of the dolichol-linked oligosaccharide (DLO) that is required for $N$-glycoprotein biosynthesis. CDG Ie is due to a defect in the synthesis of dolichyl-phosphoryl-mannose (Dol-P-Man), which is needed for DLO biosynthesis as well as for other glycosylation pathways. Human Dol-P-Man synthase is a heterotrimeric complex composed of DPM1p, DPM2p, and DPM3p, with DPM1p being the catalytic subunit. Here, we report two new CDG Ie patients who present milder symptoms than the five other CDG Ie patients described to date. The clinical pictures of the patients MS and his sister MT are dominated by major ataxia, with no notable hepatic involvement. MS cells accumulate the immature DLO species DolPP-GlcNAc ${ }_{2} \mathrm{Man}_{5}$ and possess only residual Dol-P-Man synthase activity. One homozygous intronic mutation, g.IVS4-5T $>$ A, was found in the DPM1 gene, leading to exon skipping and transcription of a shortened transcript. Moreover, DPM1 expression was reduced by more than $90 \%$ in MS cells, in a nonsense-mediated mRNA decay (NMD)-independent manner. Full analysis of the DPM2 and DPM3 genes revealed a decrease in DPM2 expression and normal expression of DPM3. This description emphasizes the large spectrum of symptoms characterizing CDG I patients. (Pediatr Res 59: 835-839, 2006)
\end{abstract}

$\mathrm{N}$-glycosylation is one of the most common protein modifications occurring on secreted and membrane proteins. $\mathrm{N}$ glycoproteins are involved in many cellular and physiologic processes such as signal transduction (via $N$-glycosylated receptors) and the immune response (1). $N$-glycans are often important for the proper conformation and activity of the $N$-glycoprotein.

$N$-glycan biosynthesis starts by the construction of a DLO in the endoplasmic reticulum (ER) membrane. Once completed, the tetradecasaccharide $\left(\mathrm{GlcNAc}_{2} \mathrm{Man}_{9} \mathrm{Glc}_{3}\right)$ of the

Received October 11, 2005; accepted January 24, 2006

Correspondence: Julia Dancourt, Ph.D., INSERM U504, Bâtiment INSERM, 16 Avenue Paul Vaillant-Couturier, 94807 Villejuif cedex, France; e-mail: Julia.GJ. Dancourt@Dartmouth.edu.

The work was supported by The Mizutani Foundation, the GIS-Institut de Maladies Rares/INSERM-funded French CDG Research Network, EUROGLYCANET (a European Community Coordinated Action: LSHM-CT-2005-512131), and institutional funding from INSERM.

The mutation g.IVS4-5T>A was made available at http://www.euroglycanet.org by the authors prior to the submission of this manuscript. Experiments were performed in accordance with the French Comités Consultatifs de Protection des Personnes dans la Recherche Biomédicale.

DOI: $10.1203 / 01 . p d r .0000219430 .52532 .8 \mathrm{e}$ mature DLO is transferred onto nascent glycoproteins containing the consensus sequence Asn-X-Thr/Ser (where X can be any amino acid except Pro). This oligosaccharide is then trimmed by ER and Golgi-resident glycosidases and glycosyltransferases to permit the proper localization and activity of the $N$-glycoprotein.

The last four mannose residues of the mature DLO are added by enzymes that use Dol-P-Man as a donor substrate. In mammals, Dol-P-Man synthase is composed of three subunits: DPM1p, DPM2p, and DPM3p (2). DPM2p and DPM3p are ER-resident, integral membrane proteins that interact with soluble DPM1p to ensure its correct localization and enzymic activity. Dol-P-Man is an important compound because, besides $N$-glycosylation, it is a substrate for $O$-mannosylation, glycophosphatidyl inositol (GPI)-anchor biosynthesis (3) and C-mannosylation (4).

CDG I are rare autosomal recessive diseases caused by deficiencies of DLO biosynthetic enzymes. Up to 12 subtypes (CDG Ia to IL) have been described to date, each one involving a different enzymic deficiency in the pathway (5). CDG I patients show a very broad range of clinical and biologic presentations, but severe neurologic symptoms are often predominant. The variation in the symptoms of this newly discovered group of diseases makes genotype to phenotype associations difficult. Therefore, patient descriptions coupled with mutation analyses are required to get more insights into the pathophysiology of the disease.

CDG Ie, which was first described in 2000, is defined by a Dol-P-Man synthase deficiency $(6,7)$, caused by inactivating mutations in the DPM1 gene. The clinical pictures of the five patients identified to date (8) are most frequently characterized by developmental delay and severe neurologic problems,

Abbreviations CDG, congenital disorders of glycosylation; DLO, dolichollinked oligosaccharide; EMT, emetine; endo H, endo- $\beta$-D- $N$-acetylglucosaminidase H; GPI, glycophosphatidyl inositol; HC, head circumference; NMD, nonsense-mediated mRNA decay; PNGase, peptide $N$-glycanase; PTC, premature termination codon; TLC, thin-layer chromatography 
among which seizures and acquired microcephaly are prominent. In cells from the patients, the Dol-P-Man synthase activity is severely diminished.

Here, we describe the first two French CDG Ie patients (siblings) who present with milder symptoms than the other CDG Ie patients so far reported. They are homozygous for a new mutation in DPM1, g.IVS4-5T >A, which causes skipping of exon 5, and transcript destabilization. Moreover, the study of Dol-P-Man synthase subunit (DPM1, 2, and 3) expression revealed that, concomitantly with a reduction of more than $90 \%$ of DPM1 transcript, DPM2 expression was reduced, while DPM3 expression was found to be normal.

\section{METHODS}

Case reports. MS, a 14-y-old boy, is the second child of consanguineous Algerian parents. He was born in Algeria after an uneventful pregnancy and delivery. He was a $3-\mathrm{kg}$ newborn who displayed early and global developmental delay dominated by severely retarded motor skills. At the ages of 1,2 , and $4 \mathrm{y}$, he presented with three episodes of febrile seizures that were treated successfully with phenobarbital. At the age of $4.5 \mathrm{y}$, he came to France for medical advice. He was tiny (height: $-2.5 \mathrm{SD}$, weight: $-3.5 \mathrm{SD}$ ), sociable, happy, and used a few words. He had microcephaly [head circumference (HC): $-3 \mathrm{SD}$ ] that was already present when $\mathrm{HC}$ was first measured at 6 mo of age. He was clumsy and unable to walk without support; stretch reflexes were brisk, and he had a convergent squint. Karyotype analysis and brain magnetic resonance imaging (MRI) were normal. He went back to Algeria for 3 y. During subsequent years, he made regular progress despite severe mental retardation with an IQ lower than 50. However, he presented with progressive neurologic deterioration with an ataxic gait, intention tremors, persistent hypotonia with signs of distal myopathy, some pyramidal signs, persistent strabismus, and nystagmus. Neurophysiological investigations have disclosed macular retinopathy, peripheral neuropathy, and mild pontocerebellar atrophy with abnormal signals in the dentate nucleus during brain MRI. Routine laboratory tests were all normal except for clotting factors with constantly decreased levels of proteins $\mathrm{C}$ and $\mathrm{S}$ that were around $60 \%$ of normal values. Liver function tests and creatine kinase (CK) levels were normal. Visceral and cutaneous examinations were normal, except for an undescended testis. Cerebrospinal fluid analysis was normal. At 9 y of age, Western blot of transferin (Tf) and orosomucoid (ORO) revealed a pattern compatible with CDG I (Fig. 1A).

MT, the younger sister (now 30-mo-old), was born after a normal pregnancy and delivery with normal neonatal measurements (height: $49 \mathrm{~cm}$, weight: $3750 \mathrm{~g}, \mathrm{HC}: 33.5 \mathrm{~cm}$ ). She was first seen at $7 \mathrm{wk}$ of age with generalized hypotonia and poor visual contact. Western blot profile of serum glycoproteins was typical of CDG I (Fig. 1A). In the following months, she displayed progressive microcephaly with a $\mathrm{HC}$ reaching $-3.5 \mathrm{SD}$ at $12 \mathrm{mo}$ of age. Moreover, she showed poor growth after the age of 12 mo despite normal food intake. Within the first months of life, it became obvious that this child was affected with a severe global retardation as at $2 \mathrm{y}$ of age she displayed a developmental score characteristic of a 6-mo-old child. She also suffered from a convergent strabismus, nystagmus, and truncal ataxia but showed a normal electroretinogram. Beside moderate cerebral atrophy, there was a hypersignal of the dentate nucleus on the T2-weighted sequence during brain MRI. Serum proteins $\mathrm{C}$ and $\mathrm{S}$ were at the lower normal range (70-75\%), while other routine laboratory investigations, including CK levels were normal. Her liver and renal analysis showed no abnormalities, except for a slight homogeneous hepatomegaly. For diagnostic purposes, genomic DNA and blood serum were taken from patient MT, but no skin biopsy was performed.

Western blot and cell radiolabeling. Serum $\mathrm{Tf}$ and ORO from patients MS and MT were analyzed by Western blot as described previously (9). Skin biopsy fibroblasts, obtained from patient MS and from a control subject, were cultured and pulse-radiolabeled with $\left[2-{ }^{3} \mathrm{H}\right]$ mannose as described previously (10). Lipid-linked and $N$-linked oligosaccharide were extracted and analyzed as described (10) and glycopeptidase F (PNGaseF, Sigma Chemical Co.Aldrich, St Quentin Fallavier, France) treatment of extracted glycoproteins was performed after denaturation $(0.1 \% \mathrm{SDS}, 50 \mathrm{mmol} / \mathrm{L} \beta$-mercaptoethanol).

Dol-P-Man synthase assay. Skin biopsy fibroblasts $\left(3 \times 75 \mathrm{~cm}^{2}\right.$ tissue culture flasks) were scraped into ice-cold phosphate-buffered saline and pelleted, and microsomal fractions were obtained as described previously (11). Dol-P-Man synthase activity was measured by incubating microsomal
A

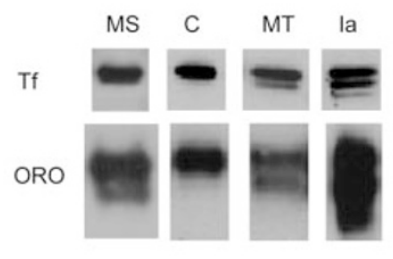

C

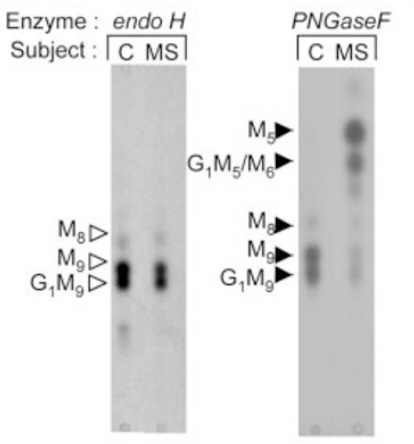

B Lipid phase: $\mathrm{CHCl}_{3} \quad$ 10:10:3 Subject : C MS $\mathrm{C} \mathrm{MS}$
Figure 1. Biochemical diagnosis of patients MS and MT (A) Western blot analysis of serum Tf and ORO from a control subject (C), a CDG Ia (Ia) patient, and patients MS and MT. (B) Skin biopsy fibroblasts from a control (C) subject and from patient MS were pulse radiolabeled with $\left[2-{ }^{3} \mathrm{H}\right]$ mannose and processed as described (10) to analyze the oligosaccharide moieties of DLOs from the chloroform and 10:10:3 (chloroform/methanol/water) phases. The oligosaccharides were submitted to thin-layer chromatography (TLC) and visualized by fluorography. The positions of standard oligosaccharides are indicated. $(C)$ Proteins extracted from MS and control cells were submitted either to endo $\mathrm{H}$ or to peptide $\mathrm{N}$-glycanase (PNGase) $\mathrm{F}$ treatment, which allowed the analysis of $N$-linked oligosaccharides by TLC. (D) A Dol-P-Man assay has been performed on microsomal fractions of control (C: $)$ and MS (MS: $\bigcirc$ ) cells. The graph expresses the radioactive Dol-P-Man as a function of the quantity of microsomal proteins. The linear regression was calculated using the GraphPad Prism software (San Diego, CA). The abbreviations used are $\mathrm{M}_{5-9}, \mathrm{Man}_{5-9} ; \mathrm{G}_{3} \mathrm{M}_{9}, \mathrm{Man}_{9} \mathrm{Glc}_{3} ; \mathrm{G}_{0-1} \mathrm{M}_{8-9}, \mathrm{Man}_{8-9} \mathrm{Glc}_{0-1} ; \mathrm{G}_{1} \mathrm{M}_{5}$, $\mathrm{Man}_{5} \mathrm{Glc}_{1}$. Open arrowheads represent oligosaccharides with one GlcNAc residue at their reducing termini, whereas closed arrowheads represent oligosaccharides with two GlcNAc residues at their reducing termini.

membrane fractions in $25 \mathrm{mmol} / \mathrm{L}$ Tris $/ \mathrm{HCl}$, pH 8 (buffer A), containing $1 \mathrm{mmol} / \mathrm{L}$ adenosyl-monophosphate, $5 \mathrm{mmol} / \mathrm{L} \mathrm{MgCl}_{2}, 0.1 \%$ (wt/vol) Triton X-100 and $1 \mu \mathrm{g}$ dolichyl-phosphate (Sigma Chemical Co.-Aldrich) in a final volume of $50 \mu \mathrm{L}$. Finally, $4 \mu \mathrm{mol} / \mathrm{L}$ GDP- $\left[{ }^{14} \mathrm{C}\right] \mathrm{Man}(248 \mathrm{mCi} / \mathrm{mmol}$, Amersham Life Science, Orsay, France) was added to the mixtures, which were then incubated for $20 \mathrm{~min}$ at $37^{\circ} \mathrm{C}$. Reactions were terminated (12), and the lower phase containing Dol-P-Man was washed twice with new upper phase before being submitted to scintillation counting.

Northern blot. Skin biopsy fibroblasts were scraped into $4 \mathrm{~mol} / \mathrm{L}$ guanidine isothiocyanate and total RNA was isolated by submitting the cell lysate to a $\mathrm{CsCl}$ gradient (13). After denaturation with either glyoxal or a formamide/formaldehyde mix, $20 \mu \mathrm{g}$ of RNA was submitted to Northern blot using standard laboratory protocols (10). As a migration standard and loading control, membranes were submitted to methylene blue (MB) staining. In some experiments, cells were treated with $100 \mu \mathrm{g} / \mathrm{mL}$ of the translation inhibitor emetine (EMT) (Sigma Chemical Co.-Aldrich) for $8 \mathrm{~h}$ before RNA extraction.

Reverse transcription polymerase chain reaction (RT-PCR), PCR, and sequencing. Total RNA and genomic DNA from the parents and the patients were extracted from peripheral blood mononuclear cells (10). Reverse transcription and PCR product sequencing were performed as described previously (10). The different primers for the PCR from cDNA are listed in Table 1. Genomic DNA was sequenced using appropriate primers (the protocols are available upon request). To obtain hybridization probes for DPM1, 2, and 3, PCR was performed on I.M.A.G.E. (I.M.A.G.E. Consortium, Washington DC) (14) clones, using specific primers listed in Table 1. 
Table 1. Primers used in this study

\begin{tabular}{|c|c|c|c|}
\hline & & Primer $\left(5^{\prime}\right.$ to $\left.3^{\prime}\right)$ & DNA template \\
\hline \multirow[t]{5}{*}{ Hybridization probes } & hDPM1 $\left(5^{\prime}\right)$ & CATGGCCTCCTTGGAAGTCAG & $3997453 *$ \\
\hline & hDPM1 (3') & ACCAGGCTTCTTTCATGTTTAACC & \\
\hline & hDPM2 $\left(5^{\prime}\right)$ & GGGAAATGGCCACGGGGACA & $4643488 *$ \\
\hline & hDPM3 $\left(5^{\prime}\right)$ & GGCCCTTCCACCTTTTG & $784484 *$ \\
\hline & hDPM3 (3') & GCTCGGGCCTCCTGTAT & \\
\hline \multirow[t]{7}{*}{ Sequencing } & hDPM1 (1S) & TCCGGCATCTGGCTCAGT & \\
\hline & hDPM1 (2AS) & GCTCATTAGGCCAGCAACTT & \\
\hline & hDPM2 (1S) & TGCGGCTCGGGTGGCTGA & \\
\hline & hDPM2 (1AS) & TCTGTCAGTCCTTCCCCAGGCTTT & cDNA \\
\hline & hDPM3 (1S) & GGCCCTTCCACCTTTTG & \\
\hline & hDPM3 (1AS) & CCGCACAGGAATGGGGT & \\
\hline & Ex4S & GGAATGAAACATGCCACAGG & \\
\hline
\end{tabular}

* I.MA.G.E. clone identification numbers.

\section{RESULTS}

\section{Biochemical Diagnosis of Patient MS}

As phosphomannomutase and phosphomannose isomerase cellular activities were found to be normal in patient MS (data not shown), CDG Ia and Ib, which are the most frequent CDG I subtypes, could be excluded $(15,16)$. We then performed $\left[2-{ }^{3} \mathrm{H}\right]$ mannose metabolic radiolabeling (10), which allowed us to detect the accumulation of dolichol-linked GlcNAc ${ }_{2} \mathrm{Man}_{5}$ in the chloroform extract of MS cells (Fig. 1B). Whereas the mature DLO species Dol-PP-GlcNAc $\mathrm{Man}_{9} \mathrm{Glc}_{3}$ is the major species in control cells, it is much reduced in both the chloroform and 10:10:3 (chloroform/methanol/water) lipid extracts of MS cells.

$\mathrm{N}$-glycans from patient MS and control cells were examined after release from polypeptide by either endo $\mathrm{H}$ or PNGase $\mathrm{F}$ treatment. Both enzymes liberated $\mathrm{GlcNAc}_{1-2} \mathrm{Man}_{9-8} \mathrm{Glc}_{0-1}$ species from both control and MS cells (Fig. 1C). However, upon PNGase F treatment MS, but not control cells, yielded additional oligosaccharides comigrating with standard $\mathrm{GlCNAc}_{2} \mathrm{Man}_{5} \mathrm{Glc}_{0-1}$. The fact that these structures were not released from polypeptides by endo $\mathrm{H}$ indicates that this species originates from DLO transfer rather than $N$-glycan trimming by the Golgi machinery.

This phenotype could be explained by a deficiency in MPDU1, ALG3, and/or Dol-P-Man synthase. MPDU1 and ALG3 gene sequences from patient MS were found to be normal, except for one heterozygous substitution (p.G685A) on MPDU1, which appeared to be a common polymorphism as it has been found with an allele frequency of $16 \%$ in 50 control subjects (data not shown). Next, Dol-P-Man synthase was assayed in membrane fractions extracted from MS and control cells and Figure $1 D$ shows that MS microsomal DolP-Man synthase activity is only $8 \%$ of the control.

\section{Molecular Diagnosis of Patient MS}

DPM1, 2, and 3 mRNA expression. Quantitative analysis of the expression of the three subunits of Dol-P-Man synthase by Northern blot (Fig. 2, EXPT1) revealed a $92.1 \%$ decrease
EXPT 1

EXPT 2

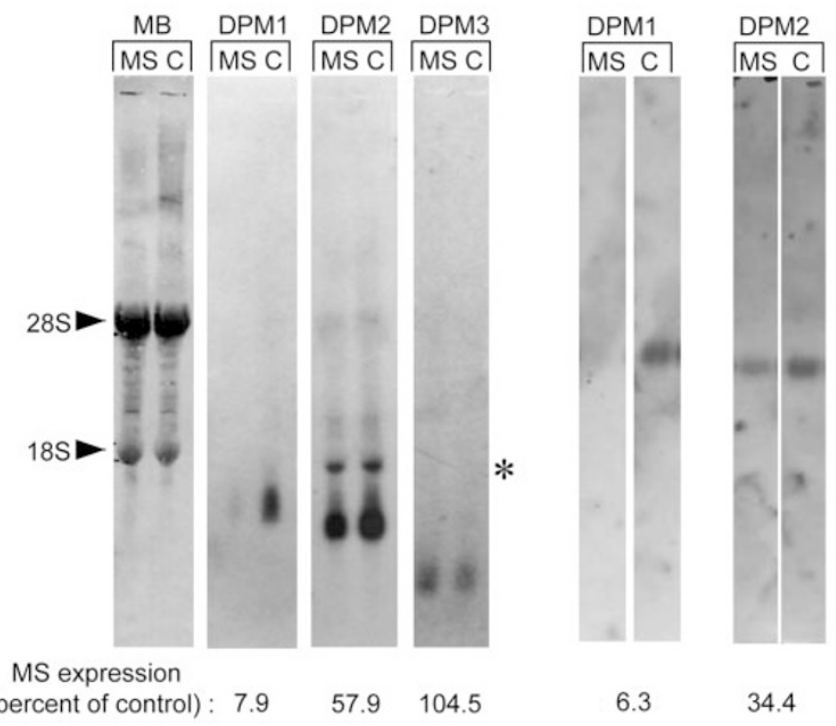

Figure 2. Northern blot analysis of DPM1, DPM2, and DPM3 mRNAs. Experiment 1 (EXPT1): expression analysis of DPM1, DPM2, and DPM3 mRNAs from control (C) and MS skin biopsy fibroblasts. RNAs were denatured by glyoxal treatment before and during migration. MB staining was performed as a loading control. $18 \mathrm{~S}$ and $28 \mathrm{~S}$ rRNAs migration positions are indicated by arrowheads. The signals were visualized by autoradiography. Quantification of the signals was performed using the Scion Image software (Frederick MD) after densitometry scanning; the data were normalized by the intensity of the 18S rRNA signal. The asterisk indicates an artifactual band in the DPM2 profile. Experiment 2 (EXPT2): expression analysis of DPM1 and DPM2 mRNA from control and MS cells. RNAs were denatured by formamide/formaldehyde treatment before and during migration. Quantification of the signal was performed after densitometry scanning.

in the expression of DPM1 mRNA in cells from patient MS compared with the level observed in control cells. Moreover, a $42.1 \%$ reduction of the expression of DPM2 was observed. Even though DPM2 expression has been shown to influence DPM3 expression (2), DPM3 sequence and expression were found to be normal in MS. These decreases in DPM1 and DPM2 expression were confirmed in a second experiment (Fig. 2, EXPT2) performed on different cell extracts and using a different Northern blot protocol. A 93.7\% reduction in 
DPM1 expression and a 65.6\% reduction in DPM2 expression were observed. By comparing the migration positions of the $28 \mathrm{~S}$ and $18 \mathrm{~S}$ ribosomal RNAs with those of the transcripts shown in Figure 2, EXPT1, we obtained an approximate size of $1.5 \mathrm{~kb}$ for DPM1, $1.1 \mathrm{~kb}$ for DPM2, and $0.9 \mathrm{~kb}$ for DPM3. The previously published sizes for these transcripts are $1.3 \mathrm{~kb}$ for DPM1, $1 \mathrm{~kb}$ for DPM2 [only one transcript described in humans (17)], and $0.49 \mathrm{~kb}$ for DPM3 (18). The larger band $(1.8 \mathrm{~kb})$ observed on the DPM2 expression pattern in Figure 2, EXPT1 was found to be artifactual as it was not observed when the Northern blot was performed using a formamidedenaturing protocol (Fig. 2, EXPT2).

Mutation analysis. DPM1 was sequenced in patient MS as well as in his affected sister and parents. A homozygous intronic point mutation, g.IVS4-5T $>$ A, was detected in MS and MT at the genomic level, and both parents were found to be heterozygous for this mutation. This intronic mutation triggers the skipping of exon 5 (Fig. 3A). The resulting shortened transcript, being the major transcript in MS, is expressed at a very low level and is predicted to encode for an in-frame premature termination codon (PTC) that leads to a severely truncated DPM1 protein (Fig. $3 B$ ). It is known that PTC-containing transcripts can be degraded by nonsensemediated mRNA decay (NMD), a mechanism that is involved in mRNA quality control and ensures the expression of only the correct transcripts (19). To test whether the truncated transcript in MS cells is a substrate for NMD, we treated the cells with EMT, a translation inhibitor known to inhibit NMD, and analyzed the resulting expression pattern of DPM1. It can be seen in Figure $3 C$ that DPM1 expression is only partially restored by EMT in MS cells.

DPM3 sequences in MS genomic DNA and cDNA were found to be normal, and two substitutions, g.213T $>C$ (silent) and g.227C $>\mathrm{G}$ (p.T76S), previously described as polymorphisms (7), were found on DPM2. These two substitutions are found at the homozygous state in patient MS and his mother, but not in patient MT and her father (heterozygous for both).

\section{DISCUSSION}

Here we describe two siblings, MS and MT, possessing a new mutation in the DPM1 gene and showing milder symptoms than previously described CDG Ie patients.
The clinical course of these siblings is remarkable by the early involvement of visual functions. Moreover, their ataxic syndrome is mainly due to neuropathy and both patients have dentate nucleus alteration without obvious cerebellar atrophy. These patients, in comparison with the previously reported CDG Ie cases, appear mildly affected (Table 2), especially as they show neither dysmorphisms nor severe epilepsy.

Like other CDG Ie patients, MS cells display an accumulation of dolichol-linked and $\mathrm{N}$-linked $\mathrm{GlcNAc}_{2} \mathrm{Man}_{5}$ and a Dol-P-Man synthase activity of less than $10 \%$ normal (Fig. 1). So what could explain the milder symptoms of MS compared with other CDG Ie patients?

The four previously described mutations on DPM1 (c.742T $>$ C, c. $274 \mathrm{C}>\mathrm{G}$, c.628delC, c.331-343del) associated with CDG Ie (8) led to amino acid changes, but were not associated with splicing defects. Patients MS and MT present a new intronic mutation on DPM1, g.IVS4 $-5 \mathrm{~T}>\mathrm{A}$, which is located on a $3^{\prime}$ splice site and is associated with exon 5 skipping. It can be seen from Figure $3 A$ that, although the DPM1 transcript level is much reduced, some transcripts have the correct size in MS cells and could therefore be responsible for the residual Dol-P-Man synthase activity. Interestingly, the reduction of DPM1 transcripts in MS cells appears to be NMD independent (Fig. 3C) and is due to a yet unknown mechanism. This reduction could be due to NMD-independent degradation mechanisms or to an mRNA synthesis deficiency caused by the use of an unusual splice site. But whatever the mechanisms involved in DPM1 mRNA trimming, exonskipping is leaky in MS cells (Fig. 3A), and it is important to note that its rate may differ between different cell types and genetic backgrounds (20). These facts could explain the lack of severe epileptic seizures in MS and the phenotypic differences between MS and MT.

Another possible explanation for the phenotypic differences between MS, MT, and other CDG Ie patients would involve DPM2. We actually observed that the expression of DPM2 mRNA was reduced in MS cells and two substitutions, one silent and one replacing a Thr by a Ser at position 76 in DPM2p, are found at the homozygous state in the MS DPM2 gene. These two substitutions have been found previously at the heterozygous state in another patient (7) expressing a normal DPM2 mRNA level. To explore a possible association
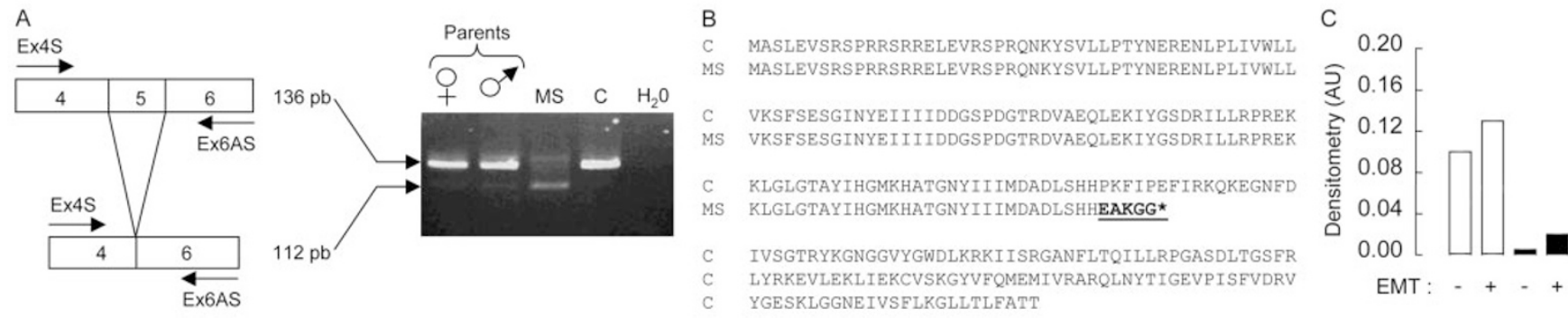

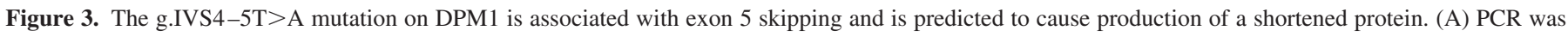

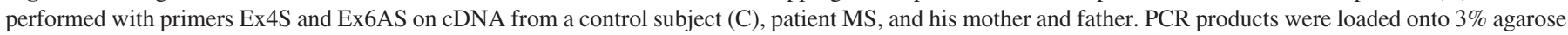

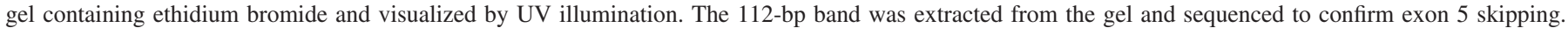

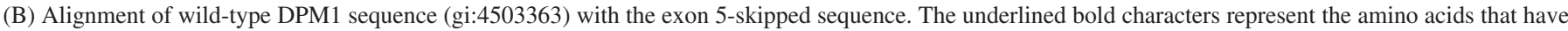

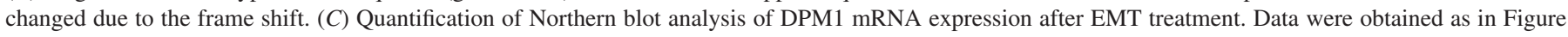
2, EXPT2. Control, $\square$; MS 
Table 2. Clinical presentation of MS and MT compared with other CDG Ie patients

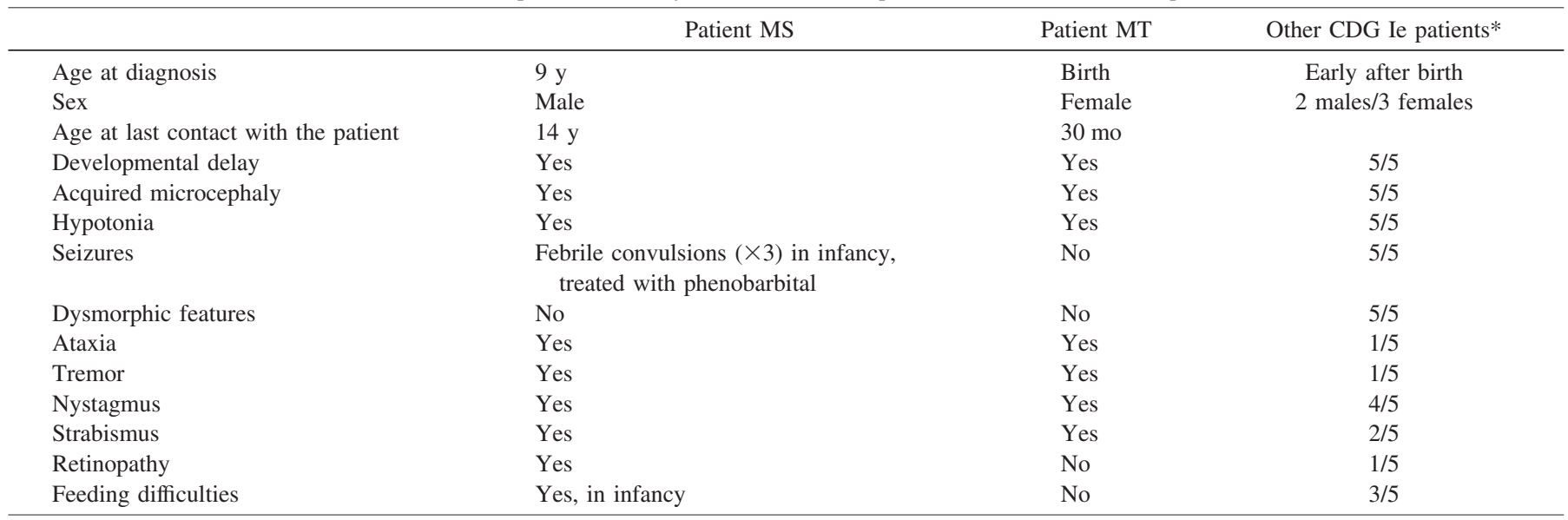

* Garcia-Silva et al. (8).

between the homozygous state of these polymorphisms and reduced DPM2 expression, it would be of interest to measure the latter in MT cells as MT is heterozygous for these two substitutions. One could hypothesize that, in the context of a faulty DPM1 expression, DPM2 would be toxic and that DPM2 mRNA level reduction would constitute an advantage for the cell.

In summary, the description of patients MS and MT adds to the number of CDG I patient reports and emphasizes the difficulties in making genotype to phenotype correlations with these patients.

\section{REFERENCES}

1. Varki A 1993 Biological roles of oligosaccharides: all of the theories are correct. Glycobiology 3:97-130

2. Maeda Y, Tanaka S, Hino J, Kangawa K, Kinoshita T 2000 Human dolicholphosphate-mannose synthase consists of three subunits, DPM1, DPM2 and DPM3. EMBO J 19:2475-2482

3. Sugiyama E, DeGasperi R, Urakaze M, Chang HM, Thomas LJ, Hyman R, Warren CD, Yeh ET 1991 Identification of defects in glycosylphosphatidylinositol anchor biosynthesis in the Thy-1 expression mutants. J Biol Chem 266:12119-12122

4. Doucey MA, Hess D, Cacan R, Hofsteenge J 1998 Protein C-mannosylation is enzyme-catalysed and uses dolichyl-phosphate-mannose as a precursor. Mol Biol Cell 9:291-300

5. Freeze HH, Aebi M 2005 Altered glycan structures: the molecular basis of congenital disorders of glycosylation. Curr Opin Struct Biol 15:490-498

6. Imbach T, Schenk B, Schollen E, Burda P, Stutz A, Grunewald S, Bailie NM, King MD, Jaeken J, Matthijs G, Berger EG, Aebi M, Hennet T 2000 Deficiency of dolichol-phosphate-mannose synthase-1 causes congenital disorder of glycosylation type Ie. J Clin Invest 105:233-239

7. Kim S, Westphal V, Srikrishna G, Mehta DP, Peterson S, Filiano J, Karnes PS, Patterson MC, Freeze HH 2000 Dolichol phosphate mannose synthase (DPM1) mutations define congenital disorder of glycosylation Ie (CDG-Ie). J Clin Invest 105:191-198

8. Garcia-Silva MT, Matthijs G, Schollen E, Cabrera JC, Sanchez del Pozo J, Marti Herreros M, Simon R, Maties M, Martin Hernandez E, Hennet T, Briones P 2004
Congenital disorder of glycosylation (CDG) type Ie. A new patient. J Inherit Metab Dis 27:591-600

9. Seta N, Barnier A, Hochedez F, Besnard MA, Durand G 1996 Diagnostic value of Western blotting in carbohydrate-deficient glycoprotein syndrome. Clin Chim Acta 254:131-140

10. Chantret I, Dupre T, Delenda C, Bucher S, Dancourt J, Barnier A, Charollais A, Heron D, Bader-Meunier B, Danos O, Seta N, Durand G, Oriol R, Codogno P, Moore SE 2002 Congenital disorders of glycosylation type Ig is defined by a deficiency in dolichyl-P-mannose: $\mathrm{Man}_{7} \mathrm{GlcNAc}_{2}$-PP-dolichyl mannosyltransferase. J Biol Chem 277:25815-25822

11. Chantret I, Dancourt J, Dupre T, Delenda C, Bucher S, Vuillaumier-Barrot S, Ogier de Baulny H, Peletan C, Danos O, Seta N, Durand G, Oriol R, Codogno P, Moore SE 2003 A deficiency in dolichyl-P-glucose: $\mathrm{Glc}_{1} \mathrm{Man}_{9} \mathrm{GlcNAc}_{2}$-PP-dolichyl alpha3glucosyltransferase defines a new subtype of congenital disorders of glycosylation. J Biol Chem 278:9962-9971

12. Babczinski P, Haselbeck A, Tanner W 1980 Yeast mannosyl transferases requiring dolichyl phosphate and dolichyl phosphate mannose as substrate. Partial purification and characterization of the solubilized enzyme. Eur J Biochem 105:509-515

13. Chirgwin JM, Przybyla AE, MacDonald RJ, Rutter WJ 1979 Isolation of biologically active ribonucleic acid from sources enriched in ribonuclease. Biochemistry 18:5294-5299

14. Lennon G, Auffray C, Polymeropoulos M, Soares MB 1996 The I.M.A.G.E. Consortium: an integrated molecular analysis of genomes and their expression. Genomics 33:151-152

15. Jaeken J 2003 Komrower Lecture. Congenital disorders of glycosylation (CDG): it's all in it! J Inherit Metab Dis 26:99-118

16. Niehues R, Hasilik M, Alton G, Korner C, Schiebe-Sukumar M, Koch HG, Zimmer KP, Wu R, Harms E, Reiter K, von Figura K, Freeze HH, Harms HK, Marquardt T 1998 Carbohydrate-deficient glycoprotein syndrome type Ib. Phosphomannose isomerase deficiency and mannose therapy. J Clin Invest 101:14141420

17. Maeda Y, Tomita S, Watanabe R, Ohishi K, Kinoshita T 1998 DPM2 regulates biosynthesis of dolichol phosphate-mannose in mammalian cells: correct subcellular localization and stabilization of DPM1, and binding of dolichol phosphate. EMBO J 17:4920-4929

18. Manos EJ, Kim ML, Kassis J, Chang PY, Wells A, Jones DA 2001 Dolicholphosphate-mannose-3 (DPM3)/prostin-1 is a novel phospholipase C-gamma regulated gene negatively associated with prostate tumor invasion. Oncogene 20:27812790

19. Frischmeyer PA, Dietz HC 1999 Nonsense-mediated mRNA decay in health and disease. Hum Mol Genet 8:1893-1900

20. Holbrook JA, Neu-Yilik G, Hentze MW, Kulozik AE 2004 Nonsense-mediated decay approaches the clinic. Nat Genet 36:801-808 